\title{
Influence of social dominance on the secondary sex ratio and factors affecting hierarchy in Holstein dairy cows
}

\author{
S. Hohenbrink ${ }^{1}$ and S. Meinecke-Tillmann ${ }^{2}$ \\ Institute for Reproductive Biology, University of Veterinary Medicine Hannover, 30559 Hanover, Germany
}

\begin{abstract}
In several studies of different species, the proportions of male and female offspring did not match the statistical assumption of 50:50. Aside from environmental and genetic factors, biological parameters were found to influence the sex ratio. Three hypotheses (TriversWillard, advantaged daughter, and the local resource competition hypothesis) have been proposed, stating that the sex of progeny might be influenced by sexbiased maternal investment in the raising of offspring. The results of existing studies are still conflicting, even within studies on the same species. The aim of the present study was to investigate whether the dominance status of cows influences the secondary sex ratio. A herd of lactating cows was observed directly for $126 \mathrm{~h}$, and a dominance index (DI) was established for 71 individuals (aged between 2.6 and $9.8 \mathrm{yr}$ ) for which at least 8 encounters had been observed to categorize individuals as subordinate, intermediate, or dominant. Furthermore, the number and sex of calves were assessed, and further individual characteristics of the animals (e.g., age, milk yield, body condition, and lameness scores) were analyzed for interrelationships with dominance status as well as the influence of the DI on the secondary sex ratio. The results indicated that the DI was independent of age, but a negative correlation was found between DI and lameness, whereas a positive correlation was shown for DI and body condition score. In general, more dominant animals had lower lameness scores and better body conditions. No sex ratio bias was found for primi- or for pluriparous animals and no seasonal influences were detected. The proportion of male offspring was significantly correlated with the DI of lactating cows, where animals with a higher social rank produced a lower proportion of male progeny. The pairwise comparison between dominant and subordinate lactating cows revealed a significant difference in the sex ratios
\end{abstract}

\footnotetext{
Received December 20, 2011.

Accepted June 28, 2012.

${ }^{1}$ Present address: Institute of Zoology, University of Veterinary Medicine Hannover, 30559 Hanover, Germany. de

${ }^{2}$ Corresponding author: sabine.meinecke-tillmann@tiho-hannover.
}

of progeny, with subordinate animals having more male calves. These results indicate that the maternal dominance rank was associated with the secondary sex ratio in cattle. These observations are generally in agreement with the advantaged daughter hypothesis.

Key words: dairy cow, secondary sex ratio, social dominance, advantaged daughter hypothesis

\section{INTRODUCTION}

Understanding and influencing the various factors that determine the sex of offspring in dairy cattle is of interest for the dairy industry, which favors the birth of female calves. One mechanism that is used to skew the sex ratio (SR) toward female calves is insemination with sex-sorted sperm, but this has high associated costs and is not affordable for many farmers. Moreover, it is of general interest whether the secondary SR (SSR) in cattle can be influenced by decisions related to their daily management. Deviations from the expected SR of 50:50 are known to occur (Jewell, 1921; Roche et al., 2006a; Silva del Río et al., 2007), and several hypotheses have been discussed to explain the mechanisms behind these patterns. The skewing of SR in cattle has been associated with the time of insemination (Martinez et al., 2004) or with AI per se (Berry and Cromie, 2007). On the other hand, a variety of studies on the SR of calves have taken into account biological issues such as season or climatic factors (Skjervold and James, 1979; Roche et al., 2006b), stress (Ideta et al., 2009), sire (Berry and Cromie, 2007), or cow-related factors (e.g., average daily milk yield, age at first calving: Skjervold and James, 1979; body condition at calving: Roche et al., 2006a).

The condition and dominance status of the mother appear to affect the SSR in mammals, but hypotheses and results have been contradictory. The Trivers and Willard (1973) hypothesis states that females in good condition should have male infants to raise strong males with great reproductive success. Subordinate mothers, however, should benefit from having female offspring rather than weak male infants with little or no reproductive success. In contrast, the advantaged daughter hypothesis (Altmann, 1980; Hiraiwa-Hasegawa, 1993) 
implies that dominant mothers should have female offspring, at least in species where the males disperse. Dominant mothers have preferential access to limited resources and benefit from having a daughter that can achieve a similar rank and obtain similar access to resources. Independently, Leimar (1996) noted that dominant mothers should have offspring of the sex with the higher investment requirement. Several studies have shown an effect of the mother's condition and dominance rank on the SSR in different ungulate species (e.g., as reviewed by Hewison and Gaillard, 1999), but the influence of dominance status on the SSR has been poorly investigated in cattle.

The aim of the present study was to determine whether the dominance rank of cows influences the SSR of calves, as has been shown for other ungulate species. This information is of interest because it would potentially allow farmers to skew the SR through changes in management. To investigate this possibility, Holstein dairy cows were ranked hierarchically, and some additional individual characteristics that affect the dominance status were analyzed. Subsequently, the effect of dominance status on the SSR was assessed, and the SSR of primi- and pluriparous cows were examined for bias.

\section{MATERIALS AND METHODS}

\section{Animals, Housing, and Management}

A herd of lactating German Holstein cows (animals included into the later analyses: 2.6 to $9.8 \mathrm{yr}$ old, mean $4.9 \mathrm{yr} ; \mathrm{n}=71$ ) was observed on a commercial dairy farm in northern Germany in 2009. The cows were housed in 1 group throughout the year in a freestall barn with a concrete floor and cubicles $(n=87$ cubicles; total barn size, $660 \mathrm{~m}^{2}$; size without feeding table, 550 $\left.\mathrm{m}^{2}\right)$. Between 111 and 116 individuals $\left(\mathrm{n}_{\text {total }}=135\right)$ were present in the barn at any one time during the observations (due to different stages of pregnancy, some cows were temporarily removed to be dried off, whereas others were reintroduced into the herd after calving, but this event was not assumed to have an effect on their previous dominance status; calvings occurred throughout the year). The animals had free access to water (3 watering sources: 2 automatic drinking basins with a length of $2 \mathrm{~m}$ and 1 automatic waterer for single animals) and a feeding table (88 feeding places; bunk face: $70 \mathrm{~cm}$ per animal). Food was delivered 3 times per day. Additionally, depending on their milk yield, individual cows obtained a specific amount of concentrated supplement in the milking robot and some glycerin if they had calved recently (2 automatic milking systems:
Lely Astronaut A2; Lely West N.V., Neuenkirchen, Germany).

\section{Behavioral Observations}

The cows were directly observed for $6 \mathrm{~h} / \mathrm{d}$ (0800 to $1100 \mathrm{~h}$ and 1300 to $1600 \mathrm{~h}$; during and after food delivery) over a period of $21 \mathrm{~d}$ in January and February 2009. Individuals were identified via numbered collars. Agonistic behaviors were monitored via "sampling all occurrences of some behaviors" (Altmann, 1974) by a single observer (S. Hohenbrink), who was positioned on the feeding table $(13 \mathrm{~m}$ long, in the center of the stable). From here, the whole barn was directly visible except for an area right behind the milking robots $\left(30 \mathrm{~m}^{2}\right)$ that was excluded from the observations. The maximum distance to the animals was $25 \mathrm{~m}$. The position on the feeding table was changed frequently, after a maximum of 10 min or when an encounter occurred and warranted closer observation. Long fights between 2 cows (recognized up to twice per week) were not evaluated. It was assumed that these 2 animals had similar dominance ranks, and a clear ending of a long fight was difficult to determine. Only dominance interactions between 2 individuals and with a clear ending were considered for later analysis. A clear ending was defined as when one of the animals was displaced (loser) by another animal (winner) or when submissive behavior such as retreating, fleeing, or avoidance occurred. In cases of avoidance, no aggressive interaction was detectable, but the subordinate evaded the dominant animal by turning around or changing sides to prevent contact or to increase the distance to the dominant cow. Agonistic behavior occurred at 2 different levels: first, without physical contact, one animal threatened another with a lowered head, sometimes combined with head movements from side to side, with abrupt pushes forward or swings of the head in the direction of the subordinate animal; second, with physical contact, head butts against the head, neck, chest, or belly region of another individual were observed. Most displacements were expected to occur at the feeding table, the watering sources, and the cubicles when the subordinate animal left its original position. Further displacements were expected at the milking robot so that the milking order was changed in favor of the dominant animal and in the form of blocking narrow passages that hindered subordinates from changing sides of the stable.

\section{Data and Statistical Analysis}

Dominance Index. The definitions of agonistic behavior for this study were adapted from Schein and 
Fohrman (1955), Galindo et al. (2000), and Phillips and Rind (2002). To classify animals into 3 dominance groups (subordinate, intermediate, and dominant), a dominance index (DI) was calculated for each individual with at least 8 clear interactions. The definition of the minimum of 8 clear interactions decreased the sample size for later analysis to 71 individuals but minimized the possibility of misjudgments of animals with low numbers of encounters. The calculation of the DI was based on the study of Galindo et al. (2000) according to the formula DI = won interactions/(won + lost interactions). Animals showing a score of 0.0 to 0.4 belonged to the lower-ranking group and were classified as subordinates (dominance level 3). Individuals with a score from $>0.4$ to 0.6 belonged to the middle-ranking group and were classified as intermediate (dominance level 2). Cows with a score from $>0.6$ to 1.0 belonged to the upper-ranking group and were classified as dominant (dominance level 1).

Lameness, Body Condition, and Additional Factors. The degree of lameness was assessed individually for each animal and was based on the definition of Sprecher et al. (1997); a 5-point locomotion scoring system was used, and animals were scored directly by a single observer (S. Hohenbrink) once during the observation period. First, the gait was assessed from a distance of approximately 7 to $10 \mathrm{~m}$ and, with the help of a research assistant, ensuring that the cows were walking straight ahead for a distance of $20 \mathrm{~m}$ on an even surface. Second, animals were observed while standing immediately after the observation of their gait. Both observations - gait and standing posturewere combined into 1 score and lasted up to 10 min per individual.

The BCS of the animals was evaluated by S. Hohenbrink according to the methods of Edmonson et al. (1989), Elanco Animal Health (1996), and Pennington (2003) using a system ranging from 1.0 to 5.0 in increments of 0.25 . All animals were scored once on the same day; therefore, the cows were in different lactation periods. The directly observed BCS was verified based on digital photos of all scored individuals (Panasonic Lumix DMC-LZ4, 5 megapixel camera; Panasonic Deutschland, Hamburg, Germany; pictures were taken from a distance of 1.5 to $2 \mathrm{~m}$ and showed the complete silhouette of the animal from the back and side as well as an angular view of the flank; intra- and inter-rater reliability: intraclass correlation coefficient $=0.93$ and 0.89 , respectively).

Both the lameness score and the BCS were determined by S. Hohenbrink at the same time that the behavioral observations were performed. At the time of estimation, the observer was blind to the dominance status of the cows, the number and sex of the cows' calves, as well as any other information about the animals. The farm's data sets were later used to calculate the stage of lactation and gestation in days. Additionally, the individual milk yields from 2009 were used for the analysis. The milk yield was calculated in kilograms per day because some animals were sold and data were not available for all $365 \mathrm{~d}$.

Data on Calves. All calves were born following AI (cryopreserved semen of 90 known and 2 unknown Holstein bulls) with sperm deposition into the uterine body. The possible influence of the bull was tested independently of the mother's dominance status as well as dependently. Data on the date of birth, sex, and number of calves born up to July 2011 were included when available. The date of birth was used to investigate seasonal differences in the SSR (October to March compared with April to September). Furthermore, the numbers of male and female calves and the SSR were compared between animals belonging to the 3 dominance levels. Additionally, the sex of the calves and the SSR were analyzed separately for the year of observation $\left(\mathrm{n}_{2009}\right.$ $=49)$ and for the previous $\left(\mathrm{n}_{2008}=57\right)$ and succeeding years $\left(\mathrm{n}_{2010}=35\right)$, both dependently and independently of the dominance level of the mothers. In a second step, the data for these $3 \mathrm{yr}$ were pooled $\left(\mathrm{n}_{2008-2010}=141\right)$. In addition, all available data on calves born from 2001 to July 2011 were compared $\left(\mathrm{n}_{\text {all calves }}=255\right)$. Whether the sex of the first calf was biased toward male or female was further analyzed independently of the ranking of the mother. Both procedures were repeated with the sex of the last-born calves of cows with at least 3 calves to find out whether any differences existed in the SSR with an increasing number of offspring per cow. Furthermore, the proportion of male calves was calculated and tested for correlation with the age of the mother. For all analyses, only live-born calves (of the 71 mothers included in the statistics) were considered, which have been registered at the central database of cattle (HI-Tier, Munich, Germany). Data on the sex of stillborn or aborted calves were not available. In the case of twin births $(n=2)$, the sex of each calf was recorded separately and analyzed independently. The 2 twin births did not affect the analyses of sex differences for first- or last-born calves.

Statistics. Data were tested with the program Statistica (version 6.1; StatSoft Inc., Tulsa, OK). Depending on the distribution of the data, correlations were tested using Pearson (parametric data: DI, stage of lactation, stage of gestation, and milk yield) or Spearman (nonparametric data: age, lameness, BCS, and proportion of male calves) tests. Furthermore, observed versus expected chi-squared tests were used to analyze the possible influences of the bull or season on the SSR and whether the sex of the first calf was biased. Addi- 
Table 1. Lameness scores (LS) and BCS (here, pooled into whole scores and not shown with increments) of lactating Holstein cows in relation to their dominance level (DL; DL $1=$ dominant, DL $2=$ intermediate, DL $3=$ subordinate)

\begin{tabular}{|c|c|c|c|c|c|c|c|c|}
\hline \multirow[b]{3}{*}{ Item } & \multicolumn{8}{|c|}{ Lactating cows } \\
\hline & \multicolumn{2}{|c|}{ DL 1} & \multicolumn{2}{|c|}{ DL 2} & \multicolumn{2}{|c|}{ DL 3} & \multicolumn{2}{|c|}{$\Sigma$} \\
\hline & $\mathrm{n}$ & $\%$ & $\mathrm{n}$ & $\%$ & $\mathrm{n}$ & $\%$ & $\mathrm{n}$ & $\%$ \\
\hline \multicolumn{9}{|l|}{ LS } \\
\hline LS 1 & 12 & 63 & 13 & 59 & 10 & 37 & 35 & 51 \\
\hline LS 2 & 6 & 32 & 8 & 36 & 9 & 33 & 23 & 34 \\
\hline LS 3 & 1 & 5 & 1 & 5 & 5 & 19 & 7 & 10 \\
\hline LS 4 & 0 & 0 & 0 & 0 & 3 & 11 & 3 & 4 \\
\hline Cows $_{\text {total }}$ & 19 & & 22 & & 27 & & 68 & \\
\hline \multicolumn{9}{|l|}{ BCS } \\
\hline BCS 2 & 4 & 21 & 6 & 27 & 17 & 63 & 27 & 40 \\
\hline BCS 3 & 15 & 79 & 16 & 72 & 10 & 37 & 41 & 60 \\
\hline BCS 4 & 0 & 0 & 0 & 0 & 0 & 0 & 0 & 0 \\
\hline Cows $_{\text {total }}$ & 19 & & 22 & & 27 & & 68 & \\
\hline
\end{tabular}

tionally, chi-squared 4-fold tables were used to compare the numbers of male and female calves between the animals in the 3 dominance levels and also independently of the mothers' rankings. An ANOVA was used to test whether the dominance status of the cows was influenced by different lactation periods (actual, previous, and succeeding). For all analyses, $P \leq 0.05$ was defined as significant.

\section{RESULTS}

\section{Dominance Index and Additional Factors}

The classification of the animals into the 3 levels of the hierarchy on the basis of at least 8 clear interactions was possible for 71 out of 135 lactating cows. In total, 19 cows were dominant (level 1: 27\%, $\mathrm{n}_{\text {pregnant }}=$ 11), 22 were intermediate (level 2: $31 \%, \mathrm{n}_{\text {pregnant }}=13$ ), and 30 animals were classified as subordinates (level 3: $\left.42 \%, \mathrm{n}_{\text {pregnant }}=19\right)$. No significant relationships between dominance and different lactation periods were found. Likewise, no significant correlation was found between the age of lactating cows and their DI. Animals with higher DI showed a significantly lower degree of lameness (Spearman rank correlation, $\boldsymbol{R}=-0.31$, $P=0.012, \mathrm{n}=68$; see Table 1 for numbers of lame animals in dominance levels). A significant correlation between lameness and age was recognized $(R=0.40$, $P<0.001, \mathrm{n}=68$ ), indicating that older animals have higher lameness scores. Furthermore, DI and BCS were significantly correlated, with dominant animals being in better condition than subordinate individuals $(R=$ $0.42, P<0.001$; see Table 1 for BCS within dominance levels). The correlation between BCS and lameness was also significant; here, a better body condition was exhibited by animals with low lameness scores $(R=$
$-0.47, P<0.001, \mathrm{n}=68)$. A significant relationship between BCS and age was not observed. When testing for correlations between the stage of pregnancy and DI, no significant correlations existed. Additionally, no significant relationship was found between the stage of gestation and BCS. Similarly, no significant correlation was observed between DI and stage of lactation of cows $(\mathrm{n}=71)$ or between milk yield and age, but DI and milk production correlated significantly (Pearson correlation $=0.28, P=0.017, \mathrm{n}=70)$, showing that animals with a higher DI have a higher milk yield.

\section{Sex Ratio of Calves and Influencing Factors}

In 70 of the analyzed animals, the sex of the calves was recorded for the actual lactation $\left(\mathrm{n}_{\text {calves }}=71\right)$, whereas data on the sex of calves from the previous lactation was available for 44 of these cows $\left(\mathrm{n}_{\text {calves }}=\right.$ 44) and for the succeeding lactation for 54 of these individuals $\left(\mathrm{n}_{\text {calves }}=54\right)$. When the sex of all calves born between 2001 and July $2011(\mathrm{n}=255)$ was analyzed, $52.2 \%$ were males $(\mathrm{n}=133)$ and $47.8 \%$ were females; thus, no significantly skewed SSR was found. To 1 bull, only male calves $(\mathrm{n}=5)$ were born, but regarding the total progeny of this individual (SSR of 8,070 registered calves: $50.4 \%$ male), no skew of the SSR was apparent. No conspicuous pattern in the SSR of offspring was found in the fathers when testing dependently or independently of the mother's dominance rank. Furthermore, no seasonal influence on the SSR or significant correlation between the age of cows and the proportion of male calves was found. A pairwise comparison indicated no differences either in the SSR of calves between individuals in dominance levels 1 and 2 or between dominance levels 2 and 3 . In contrast, the sex of offspring differed significantly between animals 
Table 2. Number and sex of calves born in different years and the sex of first- and last-born calves, differentiated between the dominance levels (DL) of their mothers (DL $1=$ dominant, DL 2 = intermediate, DL $3=$ subordinate)

\begin{tabular}{|c|c|c|c|c|c|c|c|c|c|c|c|c|}
\hline Item & \multicolumn{4}{|c|}{ Male calves (n) } & \multicolumn{4}{|c|}{ Female calves $(\mathrm{n})$} & $\begin{array}{l}\text { Male } \\
\text { first } \\
\text { calf }(\mathrm{n})\end{array}$ & $\begin{array}{c}\text { Female } \\
\text { first } \\
\text { calf }(\mathrm{n})\end{array}$ & $\begin{array}{c}\text { Male } \\
\text { last } \\
\text { calf }(\mathrm{n})\end{array}$ & $\begin{array}{l}\text { Female } \\
\text { last } \\
\text { calf }(\mathrm{n})\end{array}$ \\
\hline DL 3 & 16 & 15 & 8 & 61 & 7 & 5 & 7 & 42 & 17 & 13 & 11 & 10 \\
\hline Calves $_{\text {total }}$ & 33 & 26 & 17 & 133 & 24 & 23 & 18 & 122 & 39 & 32 & 29 & 24 \\
\hline Cows $_{\text {total }}$ & 33 & 25 & 16 & 62 & 23 & 23 & 18 & 55 & 39 & 32 & 29 & 24 \\
\hline
\end{tabular}

in dominance levels 1 and 3 (chi-squared 4-fold table, $\chi^{2}=4.35, P=0.037$, df $=1, \mathrm{n}_{\text {level1 }}=19, \mathrm{n}_{\text {level } 3}=$ $30)$, indicating a greater proportion of male progeny for subordinate animals in dominance level 3. Furthermore, a significant correlation was found between the $\mathrm{DI}$ and the proportion of male progeny $(R=-0.29, P$ $=0.015, \mathrm{n}=71$ ), showing that animals with a high DI have fewer male calves.

Similar results were obtained when the data for the periods 2009 and 2008 to 2010 were analyzed separately, showing more male calves for subordinate cows when comparing dominance levels 1 and 3 (chi-squared 4-fold table: 2009: $\chi^{2}=4.41, P=0.036, \mathrm{df}=1 ; 2008$ to 2010: $\chi^{2}=5.37, P=0.021$, $\mathrm{df}=1$; see Table 2 for number and sex of calves born in different years). Furthermore, for 2009 and 2008 to 2010, significantly more male calves were born to cows in dominance level 3 compared with level $2\left(2009: \chi^{2}=5.14, P=0.023\right.$, $\mathrm{df}=1 ; 2008$ to 2010: $\chi^{2}=4.81, P=0.028, \mathrm{df}=1$ ). When the observed numbers of male and female offspring were compared with the expected values within each dominance level, significant differences were found for animals in dominance level 3 for $2009\left(\chi^{2}=5.0, P\right.$ $=0.025, \mathrm{df}=1)$ and for 2008 to $2010\left(\chi^{2}=6.90, P=\right.$ $0.009, \mathrm{df}=1)$. Again, cows in this dominance level had a greater proportion of male offspring. For all other years, no differences in the SSR were found. This was congruent with the results obtained when the numbers of observed and expected male progeny were analyzed independently of the dominance levels for the single years 2008, 2009, and 2010 and for the pooled data for 2008 to 2010 and 2001 to 2011. Here, no significant differences between the expected and observed numbers of male and female calves were found.

Although significant correlations were obvious between DI and the 3 factors of lameness, BCS, and the proportion of male calves, neither lameness nor BCS were correlated with the proportion of male progeny (n $=68$ cows in both cases, $P \geq 0.71$ ). When the sex of the first calf of both primi- and pluriparous cows was considered, no significant correlations were found between the dominance level and the total number of male or female progeny as first offspring (see Table 2 for detailed information on the number and sex of calves). Furthermore, no significant differences were found when the sex of the offspring was assigned independently of the ranking of the mothers. Thus, no difference regarding the SSR of the first-born calves existed. When the sex of the last calf of pluriparous cows with at least 3 parturitions was considered, no significant differences were found. Furthermore, when the SSR of these lastborn calves was analyzed independently of the mother's ranking, no significant differences existed (see Table 3 for an overview of the relationships between different parameters).

\section{DISCUSSION}

In the present study, dominance indices were calculated for dairy cows and the animals were successfully categorized as dominant, intermediate, or subordinate. In contrast with young animals and adult males, when a hierarchy among adult female cattle is settled, it

Table 3. Statistical results concerning the relationships between different parameters for animals with at least 8 encounters

\begin{tabular}{lcc}
\hline & \multicolumn{2}{c}{ Lactating } \\
& \multicolumn{2}{c}{ Holstein cows } \\
\cline { 2 - 3 } Parameter & P-value & $\mathrm{n}$ \\
\hline DI $^{1}$ and age & $\mathrm{NS}$ & 71 \\
DI and lameness & 0.012 & 68 \\
Lameness and age & $<0.001$ & 68 \\
DI and BCS & $<0.001$ & 68 \\
BCS and age & NS & 68 \\
BCS and lameness & $<0.001$ & 68 \\
BCS and gestation stage & NS & 42 \\
DI and gestation stage & NS & 42 \\
DI and lactation stage & NS & 71 \\
DI and milk yield & 0.017 & 70 \\
Milk yield and age & NS & 70 \\
DI and male progeny & 0.015 & 71 \\
SSR ${ }^{2}$ and age & NS & 71 \\
SSR and season & NS & 71 \\
SSR and influence of bull & NS & 71 \\
\hline
\end{tabular}

${ }^{1} \mathrm{DI}=$ dominance index.

${ }^{2} \mathrm{SSR}=$ secondary sex ratio. 
is long-term and stable (Schein and Fohrman, 1955; Beilharz and Zeeb, 1982; Grant and Albright, 2001). Dominance-subordinance relationships persist for years (Bouissou, 1980) and are not changed by estrus or gestation (Bouissou, 1985). In a herd without considerable fluctuations in the animal population, as was the case in this study, this stability allows an evaluation of the effect of social dominance on the SSR in relation to a longer period. Removals were only temporary, occurring when some cows were removed to be dried off, whereas others were reintroduced into the herd after calving, but these events were not assumed to have an effect on the cows' previous dominance status (Bouissou, 1980). In contrast with other studies (Schein and Fohrman, 1955; Dickson et al., 1970; Albright and Arave, 1997), the rankings of the lactating cows did not depend on their ages.

A significant correlation existed between DI and lameness as well as between BCS and lameness. Furthermore, older individuals showed a significantly higher lameness score than younger ones. Lame animals are less able to cope successfully with their environment, and they will avoid initiating aggressive interactions (Galindo and Broom, 2002). According to Blowey (1998), they would also reduce their food intake, become weak, and were less able to maintain their position in the hierarchy.

The evaluation of the BCS provides the opportunity to assess the body fat stores of cows (Edmonson et al., 1989; Pennington, 2003). Subordinate animals, which are not able to prevail against other herd members, may have limited access to feeding places, which might affect their food intake and, consequently, their body condition. In this study, a significant correlation between DI and BCS was found. This might be caused by the fact that dominant animals had unrestricted access to food, water, and cubicles, whereas subordinates were chased and forced to move to other places. In situations such as this, encounters were initiated by dominant animals, which selected their favorite places whenever they wished. In contrast with dominants, subordinates did not have unlimited access to these resources and had to feed, drink, and rest under restriction, which might have an effect on the BCS. In some studies (Roche et al., 2006a; Meier et al., 2010), precalving BCS or changes in the BCS and BW between calving and conception were reported to affect the SR. However, in the present investigation, animals were scored only once, and changes in their body condition in relation to the sex of offspring cannot, therefore, be addressed.

Fregonesi et al. (2007) demonstrated that overstocking increases the competition for stalls and reduces lying time. In the present study, animals were housed under severe overstocking conditions, as not enough cubicles and feeding places were offered. The cows were overstocked up to $33 \%$, and it can be assumed that these conditions resulted in permanent stress with implications for body condition and cases of lameness in lower-ranking animals. Stress has also been shown to influence the SR of the conceptus in Holstein cattle (Ideta et al., 2009), and might represent an important factor in our own study, too. Socially or nutritionally stressed individuals have been recorded to give birth to significantly more male offspring in goats (Sachdeva et al., 1973) and deer (Verme, 1969, 1983).

A significant correlation between the DI and the proportion of male calves was observed in the present investigation: animals with a higher DI gave birth to more female calves. Thus, the results that were achieved in other ungulate species (cape mountain zebra: Lloyd and Rasa, 1989; bighorn sheep: FestaBianchet, 1991; springbok: Krüger et al., 2005) were confirmed for dairy cattle. This observation supports the advantaged daughter rather than the Trivers and Willard (1973) hypothesis. The advantaged daughter hypothesis (Altmann, 1980; Hiraiwa-Hasegawa, 1993) was established for animal species where male offspring disperse and female offspring stay with their mothers. It is known from free-living bovids (cattle: Schloeth, 1958, 1961; bison: McHugh, 1958; Meagher, 1973; African buffalo: Visscher et al., 2004) that bulls disperse and live solitary or in small groups, whereas females may remain in the group (cattle: Kimura and Ihobe, 1985), and that matrilineal bonds and kin recognition exist in cattle (Reinhardt and Reinhardt, 1981; Hagen and Broom, 2003). In groups with male dispersal, the competition between females is high. According to Silk (1983), subordinates may be unable to protect their female infants against dominant females, and their SR should, therefore, be biased toward males. Our results showed no bias in the SSR for animals in the upper or middle parts of the hierarchy, but in comparison with dominant individuals, subordinate cows had significantly more male offspring, which corresponds with the statement above. Nevertheless, some studies have not found any relationship between the dominance status of the mother and the sex of offspring in ruminants (bison: Wolff, 1988; mountain goats: Côté and Festa-Bianchet, 2001), and it might be possible that too many factors influence the SR, thereby preventing the identification of dominance as the single cause. Reports on the SR in correlation with the condition or dominance status of the mothers are controversial, even within the same species (e.g., as reviewed by Hewison and Gaillard, 1999).

In the present study was also analyzed whether changes in the SSR were evident regarding the number of births per cow. However, no differences in the numbers of male calves were found related either to 
the parity of the dams (which is in contrast to HosseinZadeh, 2012) or to their DI within primiparous and pluriparous animal groups. Other investigations regarding the SR bias of offspring in primi- and pluriparous bovids are also controversial. In the studies of Foote (1977) and Wolff (1988) on cattle and bison, no SR bias was observed. However, Rutberg (1986) recognized more male offspring in primiparous bison cows and suggested that first-breeding cows might be in better condition than lactating animals. In a study by Ansari-Lari (2006), pluriparous cows tended to have male calves, whereas Bleul (2008) reported significantly more female offspring for the same group. According to Skjervold and James (1979), no clear age trend existed in relation to parity, but the probability for dairy cattle to give birth to male calves was lower in the first and second pregnancy when the animals calved for the first time at a young age. These investigations were performed independently of the females' dominance rank.

The question of whether the sex of the last calf differs between animals of different dominance levels was investigated in cows with at least 3 calves. In contrast with findings for other ungulate species (caribou: Thomas et al., 1989; mountain goat: Côté and Festa-Bianchet, 2001), no relationship was found between maternal age and the sex of offspring, which agrees with other observations for cattle (Foote, 1977).

The intervention of management in commercial settings might have an effect on the SR in dairy cattle. It cannot be ruled out that the selling or culling of selected animals on dairy farms could support individuals producing more female offspring. Phillips and Rind (2002) suggested the separation of subordinate and dominant cows to prevent competition, primarily in feeding situations. Stress reduction is also made possible when overstocking conditions are avoided. These potentials to reduce stress situations for animals through management may, in turn, affect the reproductive success of individual animals and an influence on the SR.

\section{CONCLUSIONS}

Management strategies other than insemination with sex-sorted sperm to manipulate the sex of offspring in cattle would be an economic benefit for farmers. Although detailed observations of dairy cattle are time consuming, they may offer new ideas and management opportunities to increase the proportion of the favored sex economically if information about the individual (e.g., dominance status, condition, and welfare) could bias the SR effectively. More research is necessary to specify the most important factors that influence the SR of calves and to answer the question of whether changes in management could have an effect. The ma- ternal dominance rank was associated with the SSR in dairy cows and in agreement with the advantaged daughter hypothesis.

\section{ACKNOWLEDGMENTS}

The authors gratefully acknowledge the help, support, and cooperation of the dairy farm owners and 2 anonymous reviewers for their valuable suggestions and helpful comments on previous versions of this manuscript.

\section{REFERENCES}

Albright, J. L., and C. W. Arave. 1997. The Behaviour of Cattle. CAB International, New York, NY.

Altmann, J. 1974. Observational study of behavior: Sampling methods. Behaviour 49:227-267.

Altmann, J. 1980. Baboon Mothers and Infants. Harvard University Press, Cambridge, MA.

Ansari-Lari, M. 2006. Sex ratio at birth in dairy herds in Fars province, southern Iran. Trop. Anim. Health Prod. 38:593-595.

Beilharz, R. G., and K. Zeeb. 1982. Social dominance in dairy cattle. Appl. Anim. Ethol. 8:79-97.

Berry, D. P., and A. R. Cromie. 2007. Artificial insemination increases the probability of a male calf in dairy and beef cattle. Theriogenology 67:346-352.

Bleul, U. 2008. Influence of breed on gestation length and birth in cattle. Tierarztl. Prax. 36:171-178.

Blowey, R. W. 1998. Klauenpflege bei Rindern und Behandlung von Lahmheit. Ulmer Verlag, Stuttgart, Germany.

Bouissou, M. F. 1980. Social relationships in domestic cattle under modern management techniques. Ital. J. Zool. (Modena) 47:343353.

Bouissou, M. F. 1985. Contribution à l'étude des relations interindividuelles chez les bovins domestiques femelles (Bos taurus L.). Thèse de Doctorat d'Etat. Université Pierre et Marie Curie, Paris VI, France.

Côté, S. D., and M. Festa-Bianchet. 2001. Offspring sex ratio in relation to maternal age and social rank in mountain goats (Oreamnos americanus). Behav. Ecol. Sociobiol. 49:260-265.

Dickson, D. P., G. R. Barr, L. P. Johnson, and D. A. Wieckert. 1970 Social dominance and temperament of Holstein cows. J. Dairy Sci. 53:904-907.

Edmonson, A. J., I. J. Lean, L. D. Weaver, T. Farver, and G. Webster. 1989. A body condition scoring chart for Holstein dairy cows. J. Dairy Sci. 72:68-78.

Elanco Animal Health. 1996. Body Condition Scoring. Bulletin AI 8478 (Rev. 9/96). Elanco Products Company (1989). Eli Lilly \& Co., Indianapolis, IN.

Festa-Bianchet, M. 1991. The social system of bighorn sheep: Grouping patterns, kinship and female dominance rank. Anim. Behav. 42:71-82.

Foote, R. H. 1977. Sex ratios in dairy cattle under various conditions. Theriogenology 8:349-356.

Fregonesi, J. A., C. B. Tucker, and D. M. Weary. 2007. Overstocking reduces lying time in dairy cows. J. Dairy Sci. 90:3349-3354.

Galindo, F., and D. M. Broom. 2002. The effects of lameness on social and individual behavior of dairy cows. J. Appl. Anim. Welf. Sci. 5:193-201.

Galindo, F., D. M. Broom, and P. G. G. Jackson. 2000. A note on possible link between behaviour and the occurrence of lameness in dairy cows. Appl. Anim. Behav. Sci. 67:335-341.

Grant, R. J., and J. L. Albright. 2001. Effect of animal grouping on feeding behavior and intake of dairy cattle. J. Dairy Sci. 84(ESuppl.):E156-E163. 
Hagen, K., and D. M. Broom. 2003. Cattle discriminate between individual familiar herd members in a learning experiment. Appl. Anim. Behav. Sci. 82:13-28.

Hewison, A. J. M., and J.-M. Gaillard. 1999. Successful sons or advantaged daughters? The Trivers-Willard model and sex-biased maternal investment in ungulates. Trends Ecol. Evol. 14:229-234.

Hiraiwa-Hasegawa, M. 1993. Skewed birth sex ratios in primates: Should high ranking mothers have daughters or sons? Trends Ecol. Evol. 8:395-400.

Hossein-Zadeh, N. G. 2012. Factors affecting secondary sex ratio in Iranian Holsteins. Theriogenology 77:214-219.

Ideta, A., K. Hayama, C. Kawashima, M. Urakawa, A. Miyamoto, and Y. Aoyagi. 2009. Subjecting Holstein heifers to stress during the follicular phase following superovulatory treatment may increase the female sex ratio of embryos. J. Reprod. Dev. 55:529-533.

Jewell, F. M. 1921. Sex ratios in foetal cattle. Biol. Bull. 41:259-271.

Kimura, D., and H. Ihobe. 1985. Feral cattle (Bos taurus) on Kuchinoshima Island, southwestern Japan: Their stable ranging and unstable grouping. J. Ethol. 3:39-47.

Krüger, O., A. N. Radford, C. Anderson, and R. Liversidge. 2005. Successful sons or superior daughters: Sex ratio variation in springbok. Proc. Biol. Sci. 272:375-381.

Leimar, O. 1996. Life-history analysis of the Trivers and Willard sexratio problem. Behav. Ecol. 7:316-325.

Lloyd, P. H., and O. A. E. Rasa. 1989. Status, reproductive success and fitness in Cape Mountain zebra (Equus zebra zebra). Behav. Ecol. Sociobiol. 25:411-420

Martinez, F., M. Kaabi, F. Martinez-Pastor, M. Alvarez, E. Anel, J. C. Boixo, P. de Paz, and L. Anel. 2004. Effect of the interval between estrus onset and artificial insemination on sex ratio and fertility in cattle: A field study. Theriogenology 62:1264-1270.

McHugh, T. 1958. Social behavior of the American buffalo (Bison bison bison). Zoologica 43:1-40.

Meagher, M. M. 1973. The bison of Yellowstone National Park. Pages 38-50 in National Park Service Science Monograph Series 1. National Park Service, Washington, DC.

Meier, S., Y. J. Williams, C. R. Burke, J. K. Kay, and J. R. Roche. 2010. Feed restriction around insemination did not alter birth sex ratio in lactating dairy cows. J. Dairy Sci. 93:5408-5412.

Pennington, J. A. 2003. Body condition scoring with dairy cows. University of Arkansas, AR, Agriculture and Natural Resources, FSA4008. Accessed Aug. 10, 2011. http://www.uaex.edu/Other_Areas/publications/PDF/FSA-4008.pdf.

Phillips, C. J., and M. I. Rind. 2002. The effects of social dominance on the production and behavior of grazing dairy cows offered forage supplements. J. Dairy Sci. 85:51-59.

Reinhardt, V., and A. Reinhardt. 1981. Cohesive relationships in a cattle herd (Bos indicus). Behaviour 77:121-151.
Roche, J. R., J. M. Lee, and D. P. Berry. 2006a. Pre-conception energy balance and secondary sex ratio- Partial support for the TriversWillard hypothesis in dairy cows. J. Dairy Sci. 89:2119-2125.

Roche, J. R., J. M. Lee, and D. P. Berry. 2006b. Climatic factors and secondary sex ratio in dairy cows. J. Dairy Sci. 89:3221-3227.

Rutberg, A. T. 1986. Lactation and fetal sex ratios in American bison. Am. Nat. 127:89-94.

Sachdeva, K. K., O. P. S. Sengar, S. N. Singh, and I. L. Lindahl. 1973. Studies on goats: I. Effect of plane of nutrition on the reproductive performance of does. J. Agric. Sci. 80:375-379.

Schein, M. W. and M. H. Fohrman. 1955. Social dominance relationships in a herd of dairy cattle. Br. J. Anim. Behav. 3:45-55.

Schloeth, R. 1958. Cycle annuel et comportement social du Taureau de Camargue. Mammalia 22:121-139.

Schloeth, R. 1961. Das Sozialleben des Camargue-Rindes. Qualitative und quantitative Untersuchungen über die sozialen Beziehungeninsbesondere die Rangordnung - des halbwilden französischen Kampfrindes. Z. Tierpsychol. 18:574-627.

Silk, J. B. 1983. Local resource competition and facultative adjustment of sex ratios in relation to competitive abilities. Am. Nat. 121:56-66.

Silva del Río, N., S. Stewart, P. Rapnicki, Y. M. Chang, and P. M. Fricke. 2007. An observational analysis of twin births, calf sex ratio, and calf mortality in Holstein dairy cattle. J. Dairy Sci 90:1255-1264.

Skjervold, H., and J. W. James. 1979. Causes of variation in the sex ratio in dairy cattle. Z. Tierzuecht. Zuechtungsbiol. 95:293-305.

Sprecher, D. J., D. E. Hostetler, and J. B. Kaneene. 1997. A lameness scoring system that uses posture and gait to predict dairy cattle reproductive performance. Theriogenology 47:1179-1187.

Thomas, D. C., S. J. Barry, and H. P. Kiliaan. 1989. Fetal sex ratios in caribou: Maternal age and condition effects. J. Wildl. Manage. 53:885-890.

Trivers, R. L., and D. Willard. 1973. Natural selection of parental ability to vary the sex ratio of offspring. Science 179:90-92.

Verme, L. J. 1969. Reproductive patterns of white-tailed deer related to nutritional plane. J. Wildl. Manage. 33:881-887.

Verme, L. J. 1983. Sex ratio variation in Odocoileus: A critical review. J. Wildl. Manage. 47:573-582.

Visscher, D. R., R. J. van Aarde, and I. Whyte. 2004. Environmental and maternal correlates of foetal sex ratios in the African buffalo (Synercus caffer) and savanna elephant (Loxodonta africana). J Zool. (Lond.) 264:111-116.

Wolff, J. O. 1988. Maternal investment and sex ratio adjustment in American bison calves. Behav. Ecol. Sociobiol. 23:127-133. 